\title{
Using social listening to inform integrated social and behavior change programs in Burkina Faso
}

\author{
Nrupa Jani \\ Population Council \\ Leanne Dougherty \\ Population Council \\ Martha Silva
}

Follow this and additional works at: https://knowledgecommons.popcouncil.org/departments_sbsr-rh

Part of the Health Communication Commons, and the Public Health Education and Promotion Commons

How does access to this work benefit you? Let us know!

\section{Recommended Citation}

Jani, Nrupa, Leanne Dougherty, and Martha Silva. 2021. "Using social listening to inform integrated social and behavior change programs in Burkina Faso," Breakthrough RESEARCH Technical Report. Washington, DC: Population Council. 


\section{TECHNICAL REPORT}

\section{Using Social Listening to Inform}

Integrated Social and Behavior Change Programs in Burkina Faso

JULY 2021

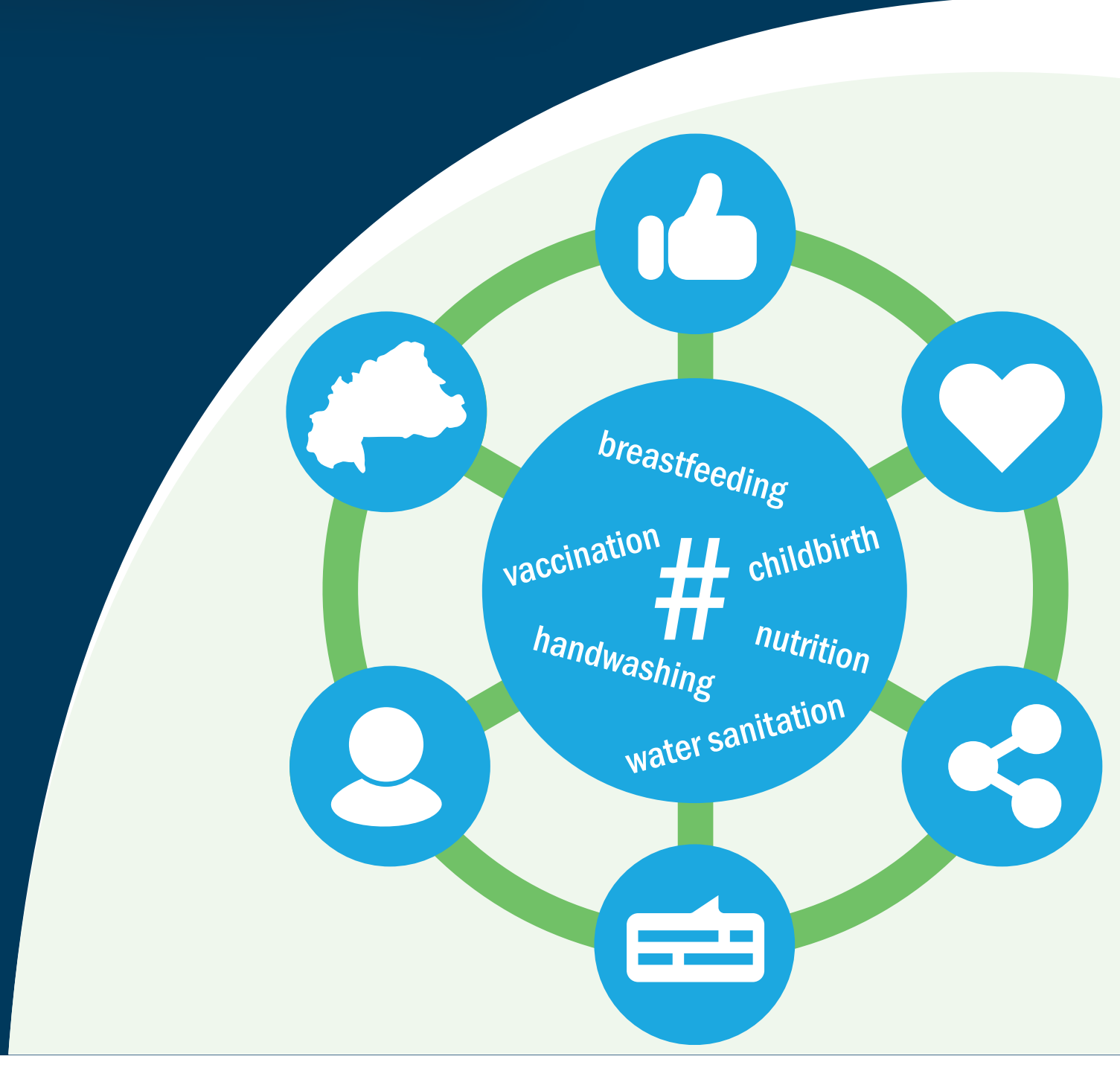




\section{Acknowledgments}

Data presented in this report were collected and analyzed in partnership with M\&C Saatchi. We acknowledge Laura Reichenbach and Amanda Kalamar of the Population Council for their technical guidance and review; Robert Pursley for editorial support; Sherry Hutchinson for design support; and Avery Avrakotos, Joan Kraft, and Angela Brasington with the United States Agency for International Development (USAID), who provided valuable feedback during the development of this report.

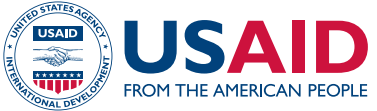

Breakthrough RESEARCH is made possible by the generous support of the American people through the United States Agency for International Development (USAID) under the terms of cooperative agreement no. AID-OAA-A-17-00018. The contents of this document are the sole responsibility of the Breakthrough RESEARCH and Population Council and do not necessarily reflect the views of USAID or the United States Government.

\section{Suggested Citation}

Jani, Nrupa, Leanne Dougherty, and Martha Silva. 2021. "Using social listening to inform integrated social and behavior change programs in Burkina Faso," Breakthrough RESEARCH Technical Report. Washington, DC: Population Council.

\section{Contact}

4301 Connecticut Avenue NW, Suite 280 | Washington, DC 20008 +12022379400 | BreakthroughResearch@popcouncil.org breakthroughactionandresearch.org

(C2021 The Population Council. All rights reserved.

The Population Council confronts critical health and development issuesfrom stopping the spread of HIV to improving reproductive health and ensuring that young people lead full and productive lives. Through biomedical, social science and public health research in about 50 countries, the Council works with our partners to deliver solutions that lead to more effective policies, programs, and technologies to improve lives worldwide. Established in 1952 and headquartered in New York, the Council is a nongovernmental, nonprofit organization with an international board of trustees.

\section{Breakthrough
RESEARCH
FOR SOCIIL \& BEAAVIOB CHANGE}

Breakthrough RESEARCH catalyzes social and behavior change (SBC) by conducting state-of-the-art research and evaluation and promoting evidence-based solutions to improve health and development programs around the world. Breakthrough RESEARCH is a consortium led by the Population Council in partnership with Avenir Health, ideas42, Institute for Reproductive Health at Georgetown University, Population Reference Bureau, and Tulane University.

\section{Tulane I University}

As stewards of the first school of public health in the United States, the Tulane University School of Public Health and Tropical Medicine cultivates independent thinkers, innovative leaders, fierce advocates, and accomplished scholars.

From the neighborhoods of New Orleans to communities worldwide, we conduct research and collaborate with our partners to ensure that all of humanity has an equitable opportunity to be healthy and pursue optimal well-being.

We train the problem solvers. Find us on the Front Lines. 


\title{
Using Social Listening to Inform Integrated Social and Behavior Change Programs in Burkina Faso
}

\author{
Nrupa Jani ${ }^{1} \quad$ Leanne Dougherty ${ }^{1} \quad$ Martha Silva $^{2}$
}

\section{PPopulation Council \\ ${ }^{2}$ Tulane University}




\section{Acronyms}

DHS Demographic and Health Survey

FP Family Planning

IVR Interactive Voice Response

LMIC Low- and Middle-income Country

$\mathrm{MCH} \quad$ Maternal and Child Health

mCPR Modern Contraceptive Rate

NGO Nongovernmental Organization

$\mathrm{RH} \quad$ Reproductive Health

RFSA Resilience Food Security Assistance

RISE Resilience in the Sahel Enhanced

SBC Social and Behavior Change

SRH Sexual and Reproductive Health

TA Technical Assistance

TFR Total Fertility Rate

USAID United States Agency for International Development

WASH Water, Sanitation and Hygiene 


\section{Table of Contents}

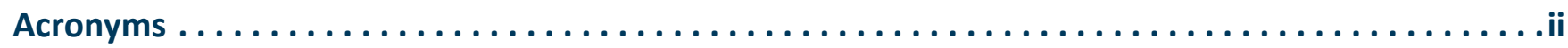

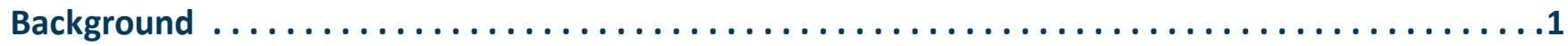

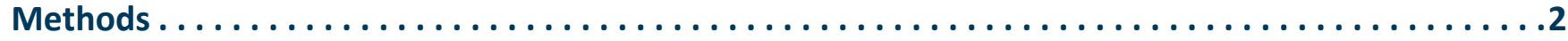

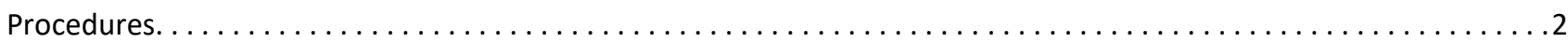

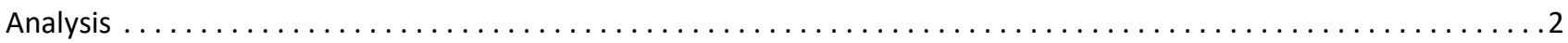

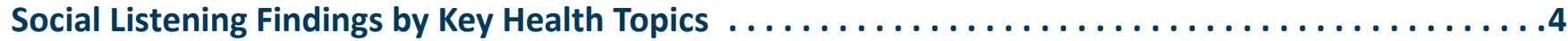

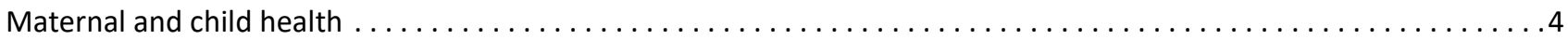

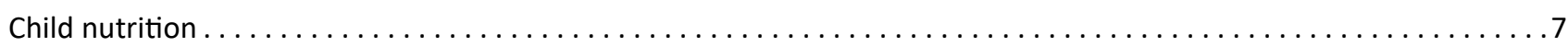

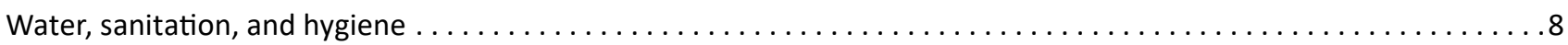

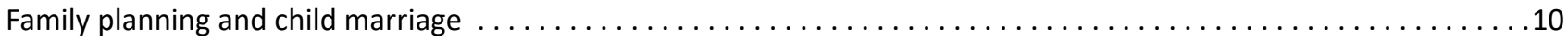

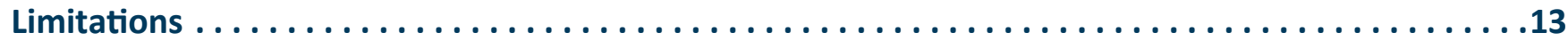

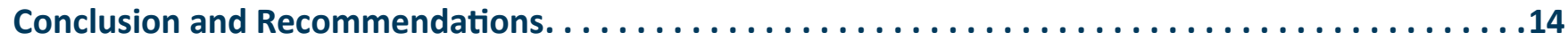

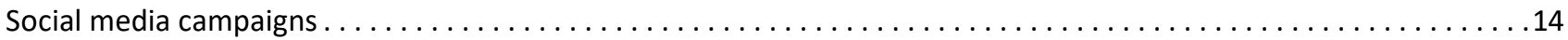

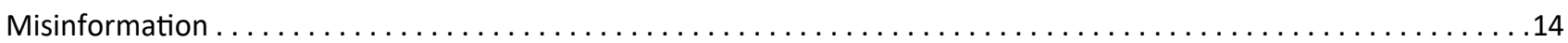

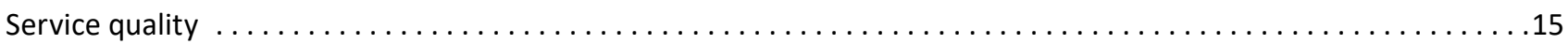

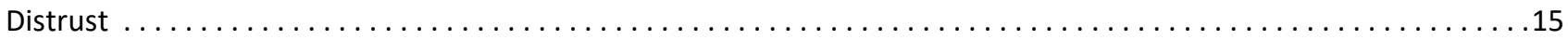

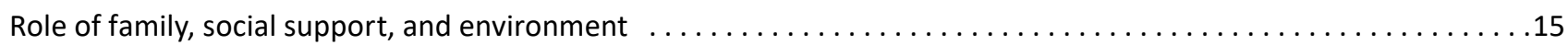

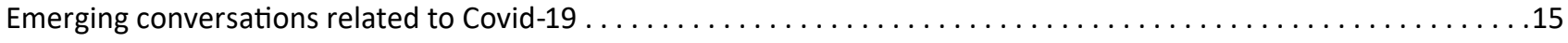

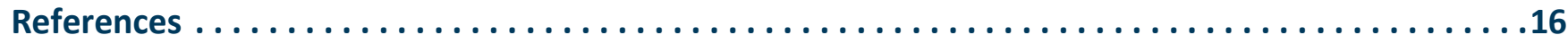




\section{Background}

Breakthrough RESEARCH - the United States Agency for International Development's (USAID's) flagship social and behavior change (SBC) research and evaluation project, in collaboration with its resource partner M\&C Saatchi, is using social listening to understand the types of health information shared through social media in Francophone West Africa. Social listening is the process of tracking conversation content and related metrics for a particular topic, program, or brand on social media. ${ }^{1}$ For social and behavior change (SBC) projects, social listening can be an important tool for better understanding people's beliefs, attitudes, and behaviors, enabling SBC programs to look at what is being said on social media, analyze the content and sentiment behind the messages-including misinformation-and use that information for program design and adaptive management. ${ }^{2}$ There is limited evidence, however, on how social listening can be utilized to inform SBC approaches for public health programs in low- and middle-income countries (LMICs). ${ }^{3}$ This report summarizes key themes emerging from social listening related to maternal and child health (MCH), family planning (FP), nutrition, and water, sanitation and hygiene (WASH) and to discuss how this information can be used to inform integrated SBC activities in RISE II program countries.

Increasing numbers of people throughout the world are using social media to access information and engage in conversations about their lives and their health. ${ }^{4}$ Usergenerated content, through websites and applications such as Facebook, Instagram, Twitter, YouTube, Reddit, blogs, and news sites, provide public health programs with a potentially rich and previously underutilized sources of data that can increasingly be used to understand cultural and religious beliefs, attitudes, and expressed social norms across health topics. While LMICs represent a relatively small share of populations using the internet, use of the internet and social media applications are growing steadily. Internet users in LMICs spend about one hour more per day on social media than those in the United States, where internet users reported spending on average two hours and three minutes online in $2020 .{ }^{4}$ As internet access and usage continues to grow in LMICs, the volume of social media conversation will rise, further increasing the availability of social media-related data.

Men in sub-Saharan Africa are primary internet users, revealing a gender gap in which women are $15 \%$ less likely than men to own a mobile phone and $41 \%$ less likely to use mobile internet. ${ }^{5}$ Similarly, social media use is higher among men than women in the region. In Burkina Faso, $16 \%$ of the population had access to the internet in 2017, with the vast majority of all users based in the capital city of Ouagadougou. ${ }^{6}$
The USAID's Resilience in the Sahel Enhanced (RISE) II program targets chronically vulnerable populations with strategies for improving priority behaviors in $\mathrm{MCH}$, $\mathrm{FP}$, nutrition, and WASH. RISE II is implemented within communities and health facilities by four Resilience Food Security Assistance (RFSA) partners and health service delivery mechanisms in selected zones in Burkina Faso and Niger. ${ }^{7}$ RFSAs use a variety of SBC approaches including community mobilization, interpersonal communication (IPC), through peer group activities, and mass media to address priority health behaviors.

To support these implementation partners, Breakthrough ACTION, USAID's flagship SBC implementation project, provides RFSA partners capacity strengthening and technical assistance (TA) to improve their coordination and enhance the quality and alignment of RISE II's SBC components. Breakthrough ACTION supports RFSAs' adoption of innovative, technology-based approaches such as messaging through Viamo's 3-2-1 interactive voice response (IVR) service. ${ }^{8}$ Breakthrough ACTION also supports RISE II SBC activities through the development of an umbrella campaign to provide a framework with a common theme for different health messages and activities implemented by the Ministry of Public Health and USAID partners. By introducing a brand image in each RISE II country, the umbrella campaign aims to create cohesion within a range of mutually supportive health topics and behaviors. 


\section{Methods}

We conducted an exploratory assessment to identify conversations taking place in Burkina Faso on social media related to $\mathrm{MCH}$, nutrition, WASH, and FP. The purpose of the assessment was to understand beliefs, attitudes, and expressed social norms of social media users in Burkina Faso related to RISE II priority health areas using social listening. We selected Burkina Faso because literacy rates, access to electricity, and internet usage are higher compared to Niger, suggesting the environment is more conducive to social media engagement.

RISE II beneficiaries reside in rural areas, likely with limited access to social media and online press coverage. However, prevailing conversations in online press coverage and social media can reveal relevant contexts for areas of health interest, including the perspectives of the government, nongovernmental organizations (NGOs), and community-based organizations, in addition to the online conversations of individuals reacting to content from these sources and stakeholders, and may provide insights for the RISE II program.

\section{Procedures}

Breakthrough RESEARCH developed a set of relevant keywords in English for capturing conversations about behaviors and care-seeking terms relevant to RISE II priority health areas. Keywords included those central to the conversation topics being studied, including, but not limited to "water sanitation," "handwashing," "breastfeeding," "childbirth," which were then entered into a Boolean search string designed to identify the most relevant conversations. The keywords were translated into French using Google Translate, and verified by French speakers to ensure accuracy.

Breakthrough RESEARCH's resource partner, M\&C Saatchi, used the Crimson Hexagon machine learning algorithm for text analysis software to analyze social media data. Crimson Hexagon software searched all

\footnotetext{
aType of search which allows users to combine keywords with operators such as 'AND', 'AND NOT', and 'OR', combining or excluding keywords in a search, resulting in a more focused and productive result. For example part of the search string for water sanitation reads: ("clean water" OR "drinking water" OR "water supply" OR "water quality" OR "water safety" OR "safe water" OR "sanitary water" OR "water sanitation") (M\&CSaatchi 2018-2019 report).
}

public facing social media for relevant conversation, including mentions from Twitter, social newsfeeds such as Burkina24.com and LeFaso, blogs, forums including Reddit, Tumblr, and YouTube. Privacy limitations relating to Facebook and Instagram did not allow private posts from these sources to be included in the analysis, and public posts from these sources were negligible.

M\&C Saatchi entered the keywords identified by Breakthrough RESEARCH into a Boolean search string and collected social media content from January 2019 through September 2020. As certain keywords generated a sizeable volume of irrelevant conversation, M\&C Saatchi refined the list of keywords to reduce irrelevant content.

\section{Analysis}

M\&C Saatchi quantified posts by each health topic the RISE II program targets and used word clouds and topic wheels to identify emerging themes in user-generated content. Findings from these analyses were summarized in 2019 and 2020 RISE II Program Support: Social Listening and Press Coverage reports ${ }^{9,10}$ and, where possible, assessed for changes in conversation volume over time. For the FP health area, the team also leveraged relevant findings from a baseline understanding social listening report from the Merci Mon Héros campaign multi-method evaluation, conducted in 2019 by M\&C Saatchi using a similar methodology of social listening described..$^{11}$ To make the detailed M\&C Saatchi reports more accessible for the RISE II partner audience, this report summarizes findings from the user-generated content related to each health area from each of these three program reports.

Merci Mon Héros (MMH, Thank You My Hero), a Breakthrough ACTION-implemented mass media campaign targeting youth and adults, promotes an environment conducive to young people's access to FP/RH services in Burkina Faso, Côte d'Ivoire, Niger, and Togo. The baseline understanding report summarizes online conversations related to FP in the four $\mathrm{MMH}$ program countries in 2019, however only findings from Burkina Faso are summarized here. Findings from all three reports-the 2019 and 2020 RISE II Program Support 
Social Listening and Press Coverage reports and the 2019 FP MMH baseline evaluation - provide extensive information on trends in conversation volume (e.g. total number of times people engaged with posts through reactions, comments, shares, retweets, mentions, and likes), sentiment analysis (i.e., a measure that reflects the tone of the keywords used in a post and is reported as positive, negative, or neutral), relevant hashtags, and extensive anonymized content data with direct quotes from user-generated content. 


\section{Social Listening Findings by Key Health Topics}

The findings of this report are delineated below by health topic. For each health topic, we first examined and summarized relevant social media campaigns and messaging from more formal sources, such as government officials or NGOs. We also examined organic online conversations about these topics taking place around the same time as social media campaigns and messaging, to understand the extent of potential misinformation, service quality issues, and related distrust in healthcare providers and services, as well as the roles of family, social support, the environment, and gender-related attitudes, as applicable. Given the timing of the analysis we also summarize emerging themes related to the Covid-19 pandemic that began in early 2020 .

Periodic increases in online conversation volume among the four main health topics were most often driven by current events or stories that inspired debate, or by popular posts that sparked online social engagement, such as likes, comments, and shares. Most social media conversation across the four health topics of interest occurred within social newsfeeds and Twitter, with a small percentage from other sources including blogs, forums, Tumblr, among others. Among all topics analyzed during the 2019-2020 study period, original posts comprised the largest single percentage of conversation, although within Twitter posts specifically, the largest percentage of conversation occurred in the form of "shares" or "retweets." Among individual users who posted content, approximately $70 \%$ were males, with little variation by health topic, ${ }^{9,10}$ which is consistent with the ratio of male users on Twitter in Burkina Faso.

\section{Maternal and child health}

Topics relating to $\mathrm{MCH}$ involved conversations related to childbirth, antenatal care (ANC), and childhood vaccinations. There were approximately 3,800 social media conversations or posts related to $\mathrm{MCH}$ from January 2019 through September 2020.

\section{Childbirth}

The total fertility rate (TFR) for women in Burkina Faso is 5.2 births per woman. ${ }^{12}$ According to the Demographic and Health Survey $(\mathrm{DHS})^{13}$ approximately one third of Burkinabe women have attended four or more ANC visits prior to their last birth, and two-thirds gave birth in a facility. ${ }^{13}$

\section{Social media campaigns}

Conversations encouraging young women to seek medical assistance for childbirth referenced the World Health Organization's global goal of zero maternal deaths. These posts were reinforced by national campaigns emphasizing the roles of health workers and midwives in supporting mothers and children. UNICEF Burkina Faso, for example, tweeted that 2,638 children were born in Burkina Faso on 1 January 2020, celebrating the "health workers who allow these children to have life." Following the UNICEF Burkina Faso tweet, the International Day of the Midwife also provided NGOs and advocacy groups with an opportunity to celebrate "\#SagesFemmes who save the lives of our children and their mothers during childbirth" (2020), suggesting a collaborative effort by advocacy groups to increase trust and improve attitudes towards midwifery. Similarly, a UNFPA Burkina Faso tweet noted, "the vital skills of midwives go far beyond childbirth they educate, empower and enable women to lead healthy lives and exercise their right to \#SSR" (2020).

A common hashtag associated with social media campaigns was \#Iwili ("bird" in Mooré), representing freedom, used as a symbol for change and means for people to seek improvement. \#Iwili often referred to improved treatment and outcome of laboring women and mothers:

For the first episode of our series
'Africa, the mothers and the
children have suffered enough in the
hospital,' a reporter at CHU Yalgado,
where the care providers are sorry to
see the poor die and the rich get better"
\#BurkinaFaso \#lwili.




\section{Misinformation, service quality and distrust}

Despite the concerted efforts of NGOs, advocacy groups, and publications lauding the work of midwives, a pointed distrust of them and health workers in general persists, evidenced in social media conversations equating treatment received by women from midwives to "violence against women" (2020), and calling for midwives to have "more humanity" (2020). Some users shared their own experiences, detailing how they "screamed in pain" (2020), and how one midwife distracted by Facebook during a childbirth almost lost a patient's life. More positive communication about the work of midwives during the Covid-19 outbreak in Burkina Faso emerged in early 2020, and was well publicized in social conversation, primarily through social media channels including UNFPA and Ouagadougou Partnership, with multiple social newsfeeds carrying articles celebrating midwives as the first line of defense against Covid-19 (2020).

Examples of disrespect and physical abuse at health centers furthered women's reluctance to engage with the health system, revealing deficiencies in health service readiness for promoting effective childbirth complication care.

\section{We had to hit the lady to open her legs and push," she says sadly. "Because we were not trained in the resuscitation of the newborn and knew that if he got stuck at this level, he would not survive." (2019)}

Lack of resources at health facilities reinforced the perception of poor quality of care as well as the reality of the inequality that exists, with some users noting that caregivers are "sorry to watch the poor die and the rich heal" (2019).

Perceptions about how women should act during childbirth, such as the belief that women should not cry when they give birth, were evidenced as practices that reinforce distrust in health centers.

As a midwife, I now tell a woman that she can cry. But before, as a woman steeped in the culture of my country, I kept telling the expectant mother to calm down, to keep quiet." (2019)
The role of family, social support, and the environment

While health system distrust, at times, is based on direct experience, it can also be passed from mothers to daughters, with many newly pregnant women advised to forego care, and they often do so as they are reluctant to reject advice from their own mothers and grandmothers. Several social media users cited examples of parents not only discouraged by their village communities from taking their sick infants to a hospital but also advised to stop breastfeeding, as it would have a negative impact on the mother. Social media users labeled family interference a significant risk during pregnancy and childbirth, as one female Twitter user pointed out:

\section{We don't talk enough about the difficulties young mothers face} with certain practices of their moms and grand moms. You say 'Don't do this' and then Grandma comes out 'that's how we raised you, don't push your white culture on us.' I know how difficult it is to go against the advice of parents, especially in children's affairs and when it is your first baby but be firm. The hospital or nothing. He is your child, not someone else's child. You carried it for 9 months." (2019)

Some social media users asserted that if more men attended their children's deliveries it could improve their quality of care and help reduce verbal and physical violence experienced by birthing women (2020). While

On en parle pas assez, des difficultés qu'on les jeunes mères face à
certaines pratiques de leurs mamans et grand mamans. Tu dis "Ne
faites pas ça" et puis la grand mère sort "C'est comme ça qu'on a
fait pour que tu sois ainsi, laisse nous vos affaires de blancs"


some reinforced the perception that fathers "don't give a damn" (2019) when a woman gives birth, an increasing number of users drew attention to the stress that fathers-to-be experience not knowing whether their spouse and child will survive the experience of childbirth. One male Twitter user posted:

At birth there are four optionseither the woman and the child survive. either the woman survives and the child dies. either the child survives and the woman dies. or both die. It's a disproportionate chance to return home with your wife and child safe and sound." (2020)

\section{Gender attitudes}

A smaller set of conversations featured men discussing the decreased attractiveness and increased weight of women after giving birth, with one male user mentioning he heard another man say that after childbirth his child's mother became fat and ugly and made him no longer want to touch her. Many users came to the defense of women after childbirth, noting how women should be cherished for their feminine beauty after birth, with one male user commenting, "It is after childbirth that we discover feminine beauty" (2019).

\section{Childhood vaccinations}

According to the DHS, vaccination rates are relatively high in Burkina Faso, with approximately $85 \%$ of children between the ages of 12 and 23 months receiving their third dose of the pentavalent vaccine..$^{13}$

\section{Social media campaigns}

In April 2019 President Roch Marc Christian Kaboré invested nearly five billion CFA francs in the country's child vaccination campaign. Prime Minister Christophe Joseph Marie Dabire Tweeted praise for the President's efforts:

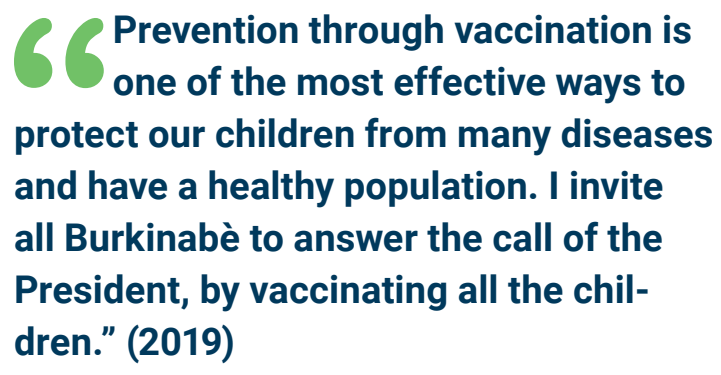

Broader social media discussion emphasized the importance of the conversation about childhood vaccinations, with famous sports players such as footballer Allison Becker using his social media presence to praise the importance of childhood vaccinations in a video discussing:

the best gift we can give our
children these holidays is the
gift of health-be sure to immunize
your children against measles \& other
vaccine-preventable diseases because
\#VaccinesWork." (2019)

\section{Misinformation, service quality and distrust}

However, it is notable that most social conversation around President Kaboré's efforts to increase child vaccination was largely driven by NGOs, advocacy groups and social newsfeeds. Conversations among individual users were more complex compared to those among policy or advocacy groups and, at times, indicated a level of distrust for vaccine safety and efficacy writ large. Some users were willing to engage in conversation on the topic, questioning whether vaccinations are compulsory for public health or driven by financial profits for the pharmaceutical industry. One social media user emphatically stated, "No to the vaccine and no to the vaccination in Africa you are not manipulating our head of state...." (2020). This view was echoed by a male user who felt that "...even when the real vaccine against Covid-19 becomes available, vaccination will be very difficult to gain acceptance in Africa. Paranoia" (2020). Given the complicated history with Western medical and vaccine trials among populations across Africa, it is not unfounded for Burkinabe social media users to express

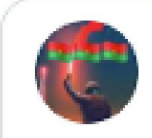

Non a la vaccin et non a la vaccination en Afrique vous pas je manipule nou chef d'État, mais nous Is jeunesse d'Afrique ont vous dire non ont né pas besoin de votre pitié vaccination en Afrique. Vive en Afrique

4:17 AM - Apr 3, 2020

0 See other Tweets


continued hesitation and distrust of potential vaccines, for treating the novel coronavirus ${ }^{14-17}$ in particular.

\section{Child nutrition}

The child nutrition topics focused mainly on diet, agriculture, and support programs, with approximately 5,300 social media conversations related to child nutrition noted during the study period.

According to the DHS, the under-five mortality rate in Burkina Faso is relatively high, at 76 per 1,000 births, and $35 \%$ of children are stunted. ${ }^{13}$ Breastfeeding was the fastest growing related sub-topic in 2020, predominantly driven by individuals and NGOs alike trying to raise awareness of its importance for infants until at least six months of age. Breastfeeding in the first hour after birth is uncommon in Burkina Faso, with exclusive breastfeeding ending prior to six months for half of all children.?

\section{Social media campaigns}

Advocacy groups, NGOs, and social newsfeeds regularly posted updates on foreign aid programs and agricultural developments, and how individuals can improve child nutrition and maintain a healthy diet. In both 2019 and 2020, conversations related to nutrition were heavily driven by NGO posts, with few public comments. In 2019, several political developments were initiated to support the President's nutrition commitment; the first was a School Nutrition and Feeding Strategy which involved a memorandum of understanding with the Gates Foundation for health, nutrition, water, and agriculture coordination, followed by a meeting with Princess Sarah Zeid of Jordan that received recognition from the World Food Program, commending progress made on child nutrition in Burkina Faso. The United Nations Development Programme (UNDP) Coordinator in Burkina Faso publicly lauded President Kabore's commitment to improving the state of nutrition in the country, noting:

\section{The president of Faso is a cham- pion of nutrition, because he knows that nutrition is the basis of good health, growth and prosperity, especially for Burkinabè mothers and children." (2019)}

Again, \#Iwili was one of the frequently used hashtags, along with others including \#FaimZero (Campaign for Zero Hunger by 2030) and \#II_Est_Temps_D_Agir (It Is
Time to Act), and the more predictable \#Nutrition, denoting priority and progress in child nutrition.

Conversations related to breastfeeding were likewise driven by individuals and NGOs trying to raise awareness of the importance of breastfeeding infants until at least six months of age. An increase in conversation volume occurred in June 2020 with the launch of the regional "Stronger with Breast Milk Only" campaign that encouraged not providing babies with water until at least six months of age. Several organizations championing breastfeeding, including UNICEF Burkina, spread awareness of the importance of breastfeeding on social media by highlighting World Breastfeeding Week and publishing messages such as, "Of all possible and imaginable interventions, breastfeeding babies is the one that saves the most lives" (2019). Social media users expressed enthusiasm for the campaign, with supporting posts from a female National Champion for Nutrition, noting, "Exclusive breastfeeding until 6 months is an essential link in the fight against chronic malnutrition" (2019), and a male Twitter user posting: "There is no 'the baby is thirsty we will give him a little water....' Leave them alone, let them grow up normally! Say it around you" (2019). Many social media users volunteered positive experiences from their own breastfeeding journeys in response to the campaign. One female noted the importance of her breastfeeding in a Tweet: "because in breast milk there are more nutrients than in normal milk" (2019), evidencing the fact that non-human milk, or "normal milk," is considered the norm in Burkina Faso. A male user suggested that breastfeeding is imperative until your children have grown teeth, to give them the best chance in life and ensure that they will be around "when you have lost yours [teeth]" (2019).

\section{Misinformation, service quality and distrust}

One recurring child nutrition theme was the "fat belly": whereby social media posters kept asking how children with enlarged stomachs, often viewed as a sign of affluence, could be malnourished demonstrating that misinformation about the consequences of malnutrition still exist among many social media users, who questioned, "how can they be malnourished if they have a fat belly," and "is the fat belly a synonym for affluence?" (2019).

\section{Emerging themes related to Covid-19}

In March 2019, President Kaboré unveiled a school feeding program to "provide each school-aged child with at 
UNFPA Burkina Faso

(OUNFPABF

\#Rt @ONUinfo

\#COVID19 et femmes enceintes

Vous pouvez continuer à allaiter :

- Respecter les règles d'hygiène respiratoire

$\rightarrow$ Se laver les avant de toucher le bébé $\&$ après

- Nettoyer \& désinfecter régulièrement les surfaces

bit.ly/34vUIIM via @WHO

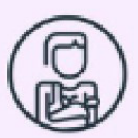

Les femmes touchées par la COVID-19 peuvent allaiter si elles le souhaitent. Elles doivent :

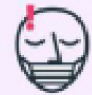

Respecter les règles d'hygiène respiratoire et porter un masque, si possible

Se lawer les mains avant de toucher le bébế et après

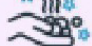

BR:- Nettoyer at désinfecter

régulièrement les surfaces

\section{6. by World Health} Organization

\#COVID19 \#CORONAVIRUS

9:20 AM - 17 avr. 2020

least one good quality meal and in sufficient quantity per day" (2019). The initiative was well received, with associated positive social media sentiments increasing from an average of 20\% to 53\% during the one-week period preceding the campaign's official launch. Most of the positive sentiments were driven by political and social channels sharing the story on social media, or in positive news articles from popular sources including Sidwaya. info and Burkina24, published on social newsfeeds, with otherwise little organic public conversation about the strategy. Despite the promising launch, the coronavirus outbreak in early 2020 resulted in school closures, causing millions of children across the country to miss their one guaranteed meal per day. UNICEF Burkina noted,

For millions of children, the meal they eat at school is the only one they get in a day. We must act now to prevent the \#COVID19 pandemic from becoming a hunger catastrophe." (2020)
The topic of re-opening schools after the Covid-19 outbreak was prevalent throughout NGOs and advocacy group discussions. @ONUinfo stated, "School is more than a place of learning. For many children, it is a lifeline for safety, health services and nutrition" (2020). Debate on safe re-opening of schools has been ongoing and widely covered in articles on social newsfeeds.

Some believed coronavirus discussions drew focus away from hunger and the virus's impact on child malnutrition. One male Twitter user noted:

\section{There is also a virus called \\ 'HUNGER' that kills almost 8,000 children a day around the world, the anti- dote exists and it's called 'FOOD'.... But we don't show that on TV." (2020)}

Such discussions attempted to remind users that amidst the coronavirus pandemic and discussions about re-opening schools to provide many children with their most substantive meal of the day, to not forget about the ongoing twin pandemic of hunger and its impact on malnutrition. There was also a spike in volume on the related topics of breastfeeding and Covid-19, with people initially unsure of the virus's implications for breastfeeding. A UNFPA Burkina Faso post from @UNFPABF was shared relatively early in the pandemic and retweeted numerous times as people employed their online social networks to spread awareness of new best practices for breastfeeding, safely and hygienically.

\section{Water, sanitation, and hygiene}

Conversations relating to WASH mainly discussed water sanitation infrastructure, drinking water, and disease spread. While access to clean, potable water sources is advancing in Burkina Faso, there is a critical need for improved sanitation facilities. While $75 \%$ of households reported at least one designated place for handwashing by location, only $24 \%$ of households reported using improved sanitation facilities. ${ }^{13}$ Social media conversations suggested an understanding of the importance of handwashing during the 2020 Covid-19 pandemic and appropriate techniques for disinfection, with efforts to dispel associated rumors and misinformation. There were approximately 3,400 social media conversations related to WASH between January 2019 and September 2020. 
UNICEF Burkina Faso

@UNICEF_Burkina

\section{Choléra \\ Diarrhée \\ Malnutrition}

Les maladies liées à la qualité de l'eau sont I'une des causes principales de mortalité chez les enfants de moins de 5 ans.

L'UNICEF et ses partenaires travaillent pour que chaque enfant ait accès à de l'eau potable. \#WorldWaterWeek

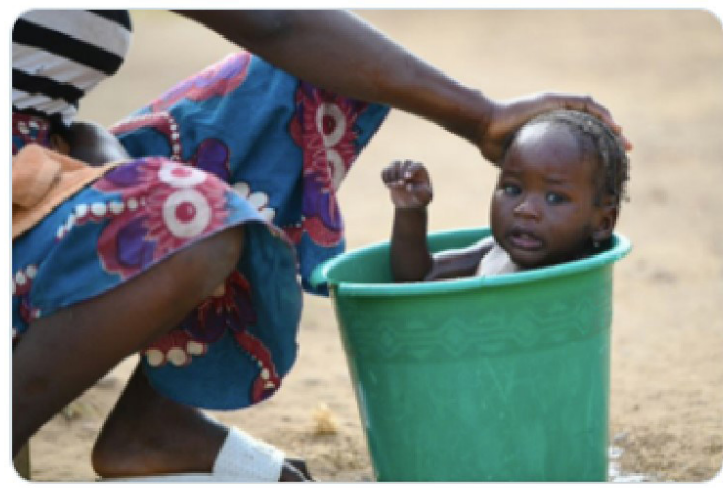

8:00 AM - Aug 27, 2019

(i)

\section{Social media campaigns}

In May 2019, Burkinabe authorities launched a water supply and sanitation program, setting a national goal of providing drinking water and wastewater treatment facilities to 1.16 million citizens $(630,000$ urban residents and 53,000 rural residents). Several NGOs and foreign aid organizations also used the opportunity of Global Handwashing Day on October 15 to remind children of the importance of protecting their health by a simple and effective handwashing routine, in hopes of reducing child deaths from water-related diseases.

\section{Misinformation, service quality and distrust}

Despite the government's water and sanitation program, conversations on social media were seemingly driven by frustration with poor quality drinking water, delays in planned infrastructure projects, frequent water supply shortages, and poor sanitation. Social media users frequently complained about the quality of local water supplies. Several male and female users noted that just as they were "about to go wash" they realized the "water is cut" (2019). This recurring complaint suggests water service quality in many areas of Burkina
Faso remains sub-par, despite government emphasis on achievements in improved access to drinking water and press coverage of water sanitation projects. Social media posts across the country revealed a deeper frustration behind the promises in positive media coverage. One male Twitter user posted: "Access to drinking water in certain regions and even in certain urban cities is really difficult. The authorities must find solutions for the well-being of the populations," (2019) while UNICEF Burkina emphasized that "drinking water is not a luxury, it is a right!" (2019).

\section{Emerging conversations related to Covid-19}

The coronavirus pandemic that emerged in March 2020 exacerbated ongoing WASH concerns in Burkina Faso, with social media users quick to point out that people lack not only access to clean water but also hand sanitizer as a means of protecting themselves, with one female Twitter user posting: "People have emptied the pharmacies of hydro-alcoholic gel and the price is only going up" (2020). At the onset of the outbreak, conversations about proper handwashing and sanitizing were prevalent, with users seeking to share information about steps to mitigate spread of the virus. One female Twitter user noted,

\section{We stay at home, we haven't been going out since Monday (except emergencies) We did some shopping.}

\section{monpo Mondoblog \\ (@) mondoblog}

Non, se laver le corps avec de l'eau chaude ou de la javel ne protège pas du \#COVID19

\#Infox \#coronavirus \#Niger \#Sahel \#Santé

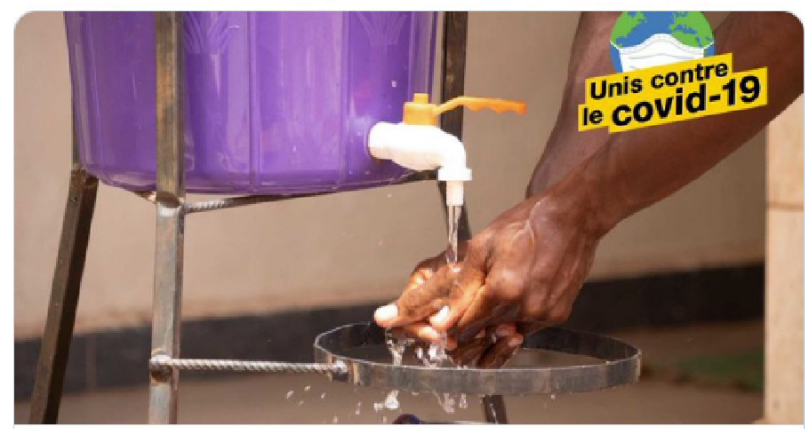

\#Askip : Ả ce qu'il paraît, se laver le corps avec de l'eau chaude ou de l.. Il y a quelques jours, j'ai surpris une conversation entre des jeunes du quartier sur le coronavirus. L'un d'entre eux encourageait ses amis à s.. $\vartheta$ influenceurmedia.mondoblog.org

11:08 AM - 16 juil. 2020

O $7 \quad$ Voir les dernières informations sur le COVID-19 sur Twitter 


\section{We wash our hands almost all the time. We are constantly on the news channels. Mom sprays bleach on the door handles." (2020)}

Many social media users attempted to dispel misinformation about the virus (e.g., hot water and bleach baths do not protect against Covid-19) and discredit false rumors, in addition to disseminating correct information about the virus and how to protect oneself, despite ongoing water challenges and hand sanitizer shortages. Blogging community Mondoblog made efforts to dispel Covid-19 misinformation by encouraging washing with soap and water, not bleach.

During the July 2020 Minister of Water's TV appearance, it was announced that the Ministry of Water and Sanitation budget was reduced around 12 billion FCFA to contribute to response actions against the coronavirus. Many on social media were quick to note the paradoxical nature of the decision, given that "More than 4,000 [school] establishments do not have water points and more than 2,000 do not have sanitation points at \#BurkinaFaso" (2020) as one male Twitter user noted, seeing as "We need 50 billion to provide every school with water and sanitation services" (2020).

\section{Family planning and child marriage}

Family planning and contraception conversations featured the second highest proportion of female social media users. The topic of child marriage comprised $10 \%$ of relevant social conversation in Burkina Faso during 2020 (down from 27\% in 2019), with the country's media raising awareness of this pervasive issue as part of efforts to eliminate the practice.

\section{Family planning}

Burkina Faso's TFR is 5.2 births per woman ${ }^{12}$ and the modern contraceptive prevalence rate (mCPR) in 2018 was $27.3 \%{ }^{18,5}$ More than half of Burkina women are married by the age of 18 , with $29 \%$ of girls having given birth by 18 years of age. ${ }^{12}$

\section{Social media campaigns}

As in other health domains, FP advocacy organizations including the Ouagadougou
Partnership, UNFPA, UNICEF, and FP2020 drove much of the social media conversation on FP, with considerable spikes towards the end of 2019, coinciding with the publication of two FP-related articles: the first promoting FP in Burkina Faso and the second discussing how FP is not prohibited in Islam. Notably, \#lwili was again a frequent hashtag in conversations related to FP, following the announcements of new, related FP projects by Amplify PF and Breakthrough ACTION in July 2019.

\section{Misinformation, service quality and distrust}

Costs were cited as a common factor limiting access to contraception among women in Burkina Faso, along with recognition of the need for increased availability of a wider range of contraceptive methods to ensure available methods meet $\mathrm{MCH}$ needs and help reduce the likelihood of discontinuation. One social media user noted, "A wide variety of family planning methods need to be made universally available to improve maternal, newborn and child health" (2019).

\section{The role of family, social support, and the environment}

Several social media users mentioned the importance of religious teachings and leaders in influencing decisions about contraceptive use. Conversations centered on religion more specifically debated what does and does not make God happy, in relation to sexual activity and contraceptive use. Some particularly harmful opinions of women are apparently a result of religious teachings and the types of sexual behavior believed to be acceptable, or unacceptable, to God, with one user comparing the "vice of woman" to the Biblical serpent from Adam and Eve.

Conversations related to FP had the highest proportion of female participants, with most sharing positive attitudes about specific FP topics. These conversations tended to focus more on condoms as a means of preventing pregnancy or sexually transmitted diseases, rather than pills and injectables typically used for the healthy
L'utilisation d'un préservatif est un signe que vous avez des relations sexuelles avec une personne avec laquelle vous n'êtes pas censé avoir des relations sexuelles. Ai-je raison ???

$142: 43$ PM $=$ Oct 11, 2019 
pregnancy timing and spacing among married couples. This may be because nearly all internet users in Burkina Faso are based in the capital city of Ouagadougou, with more diverse social norms related to sexual behavior. A common theme among both male and female users implied that condom use signifies a person is having sex with someone illicitly; one user implored, "please use a condom" (2019), specifically if sleeping with someone you do not intend to have a serious relationship with.

\section{Gender attitudes}

Much online conversation revealed potentially harmful gender attitudes not supportive of safe sexual health or FP. These conversations revealed sexist attitudes blaming women for unintended pregnancy, with no expectation of couples developing a shared understanding of the need for contraception to avoid pregnancy. Male social media users joked that a woman says, "We are pregnant; you refuse; and they abort." Some women also blamed others for becoming pregnant, with one female user posting: "Stop getting pregnant in a mess take the pill or condoms are also present 2019[.] We are fed up with your accidental pregnancies" (2019).

These conversations revealed greater use of female terminology indicating that women were discussed and mentioned far more than men, also suggesting that women are held more accountable than men in pregnancy prevention. Women are expected to "have an ounce of dignity and prudence" (2019) rather than speak openly about sexual behavior. At the same time, women were also ridiculed by men for "acting saintly" and refusing to admit they also enjoy sex. A female Twitter user lamented the fact,

\section{When a woman declares that she likes sex, in your eyes she auto- matically becomes an easy girl. You think that only you men have the right to love and practice sex any way you want." (2019)}

The hashtag \#ThursdayConfession began trending to reveal a sense of "\#guilt" among women, further insinuating that women who enjoy sex are considered "easy." Another male user proclaimed that girls who flirt with men out of boredom are "dark whores," disregarding men's similar behavior, without societal reprimand.

Some social media users tried to normalize the idea that women should have the right to the same choices as men, without fear of being shamed. One Twitter user insisted that regardless of who a woman has slept with in the past, she has free choice to decide whom she sleeps with in the future. Another stated that there should be no shame in buying condoms because it is a responsible sexual and reproductive health (SRH) behavior.

\section{Child marriage}

According to a UNICEF report cited by a popular news website in Burkina Faso, Siwaya.info, approximately 52\% of girls in Burkina Faso are married before 18 years of age, and $10 \%$ before age $15 .{ }^{9}$ Adolescents in Burkina Faso are also less likely to be equipped with adequate SRH knowledge, and sexually active adolescents are less likely to use contraception. ${ }^{19}$

\section{Social media campaigns}

Several groups such as @UNFPABF, @POuagaPF, and the Alliance of West African Religious for Health Promotion and Development posted regularly about child marriage, in efforts to raise awareness, and Twitter users shared numerous messages highlighting its prevalence, citing

\section{Ces images montrent un mariage d'enfant qui est puni par la loi. \\ On doit retrouver le couple et vérifier l'âge de l'adolescente \\ @LorenceKabasele @annytenga @audreykabanga \\ @PZamuda @AstridTambwe @ffcrdc @sofepadi \\ @CoalitionGnd @richinem79 @ChantalFaida \\ @MbiyaJeff @SoleneTshilobo2 \\ Translate Tweet}

\section{Q ABEF-ND RDC @abefnd_rdc. Jun 3, 2019}

La santé sexuelle reproductive de qualité devrait être efficace pour tous les jeunes s'assurant qu'ils sont protégés contre les mythes et les idées fausses entourant l'information de santé reproductive sexuelle ainsi tous les jeunes obtiennent l'accès aux services réactifs de SSR

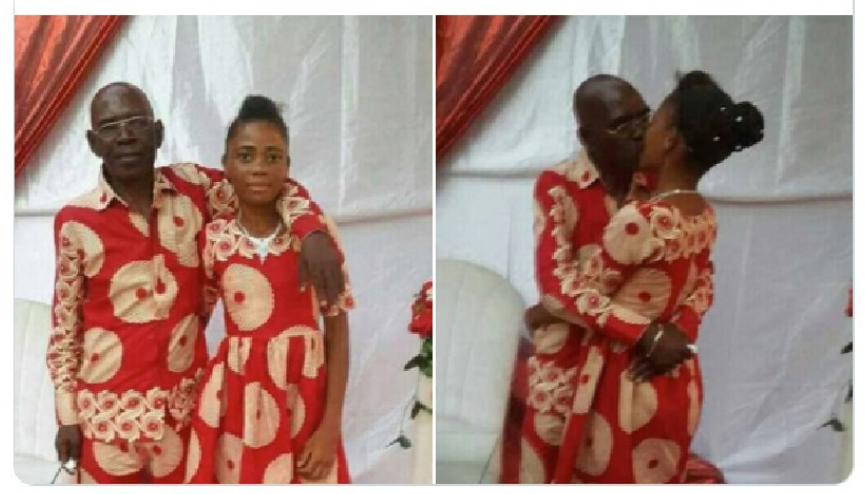

5:42 AM - Jun 3, 2019 - Twitter for iPhone 
that "Burkina Faso has the fifth highest prevalence of child marriage in the world" (2020). Social media users reported health problems for girls giving birth as well as deficits among children resulting from child marriage, with many quick to point out the practice is incredibly dangerous. Not only are child brides being married to men of any age, but when girls as young as 13 give birth, "she has complications because her body is not developed enough for that" and the baby is subsequently "malnourished and her 'mother' does not know how to take care of it" (2019). In August 2020, Burkina Faso's President's wife, Ms. Sika Kaboré, called on the country's media to continue to play its part in drawing attention to child marriage:

\section{It is certain that the elimination of the practice of child marriage and of all practices harmful to the health of women and children cannot be achieved without the significant contribution of the press." (2020)}

\section{Emerging conversations related to Covid-19}

The 2020 coronavirus pandemic also brought child marriage to mainstream discussion, as the ability and right to a classroom education was compromised for many children during the pandemic, with girls at a disproportionate risk due to lack of parental resources and increased exposure to potential gender-based violence and child marriage (2020). Users echoed the President's wife's sentiments, calling on social networks to raise awareness and 'fight child marriage, increase girls' education and promote adolescent health by addressing gender specificities and responding to gender-based violence" (2020), as one female Twitter user pleaded, utilizing the hashtags \#EndChildMarriage, \#EndViolence, and \#GirlsGetEqual. 


\section{Limitations}

While this exploratory assessment provided a novel opportunity to review how individuals discuss health topics through social media, there are several limitations to consider with this approach. First, conversational volumes should not be taken as complete or exhaustive, as search strings were created to minimize irrelevant conversations, which may not adhere to intended nuance. Additionally, many posts could be considered to span across multiple topic areas, such as child marriage, but are assigned to a single topic area, in this case FP, but with discussion and implications also applying to other topics. Second, the social listening analysis in this study gleaned data from public facing social media platforms including YouTube comments, blogs, forums, Twitter, Pinterest, Reddit, and Tumblr. Private posts on large social media platforms such as Facebook, Instagram, and WhatsApp were not included in this analysis due to privacy policies that do not allow for inclusion. Third, while Google Translate was used to include mentions in French, local languages and vernacular were not included thus, the perspectives of those commenting in French may not be representative of those who choose to express themselves in local languages. Similarly, as noted, those with access to social media are not representative of those without access, in particular populations served by RISE II implementing partners who are less likely to have access to social media. Future social listening analyses should attempt to consider social media posts in local language and vernacular to be more representative of the population, specifically those who may be of lower socioeconomic status and reside outside Ouagadougou, to be represented in discussions and findings. 


\section{Conclusion and Recommendations}

Social listening can be an important tool for understanding the beliefs, attitudes, expressed social norms, and behaviors of social media users. Social listening enables SBC programs to look at what is being said on social media, analyze the content and sentiment behind the messages-including misinformation-and use this information for program design and adaptive management. The themes identified in this social listening study suggest that programs should address population concerns linked to misinformation, service quality, and distrust of health services; factors related to family, social support, and the environment; and continuous monitoring of emerging conversations related to Covid-19, to respond to challenges resulting from misinformation and complicating adoption of priority health behaviors.

We used social listening to understand the beliefs, attitudes, and expressed social norms of social media users in Burkina Faso relating to RISE II priority health areas. Noting that the vast majority of internet and thus social media users in the country reside in the capital city Ouagadougou, of the individual users who posted content, the majority were males with little variation across health areas..$^{9,10}$ On average, there were between 1,700 and 3,000 posts each year for each priority health topic. During the study period (January 2019 -September 2020) child nutrition inspired approximately 5,300 social media conversations, $\mathrm{MCH}$ approximately 3,800 posts, and WASH about 3,400.9,10

Positive trends in conversation volume tended to cluster around announcements of related policy developments by the government, such as the launch of the President's vaccination campaign for children or World Water Day. Similarly, NGOs such as the Alliance of West African Religious Leaders for Health Promotion and Development led promotion efforts through social media in 2019 to address the issue of child marriage, which led to associated conversation spikes.

Below we outline recommendations for how these cross-cutting findings can be applied by RISE II implementing partners and Breakthrough ACTION to create cohesive messaging for their umbrella campaign strategy development in Burkina Faso that will have relevance and resonate with people's lives and invoke a source of motivation for lasting SBC in the country and region.

\section{Social media campaigns}

- \#lwili is a symbol for change and improvement that resonates with many people and provides motivation for target audiences, while cutting across the priority health behaviors. Consider concept testing the hashtag \#Iwili (meaning "bird" in Mooré) as a unifying theme for multiple health topics using a recognizable logo, as \#lwili is currently used in social media posts relating to priority health outcomes.

- The Breakthrough ACTION led umbrella campaign should reinforce messages for priority health areas by coordinating efforts with existing international campaigns, such as those by UNICEF and UNFPA Burkina Faso, including those featuring public figures to promote their campaigns, as well as government policies.

- Conduct social listening to monitor engagement with national campaigns as social media and internet access increases and identify insights where additional effort is needed.

\section{Misinformation}

- Establish continuous feedback loops through rapid surveys and social listening to help identify dangerous misinformation and practices over time, such as the belief that vaccines are unsafe, that garlic water can cure Covid-19, or that breastfeeding has negative impacts on mothers.

- Work with religious leaders to promote and reinforce FP messaging that dispel myths about acceptable forms of contraceptive use, including condoms, particularly by women.

- Liaise with community and advocacy leaders to address misinformation by breaking the cycle of its repetition or retweeting on social media platforms, limiting direct engagement with dubious sources of information, reporting it to social media companies, and providing accurate information, for instance, the prevention and spread of Covid-19, or maternal newborn feeding practices. 


\section{Service quality}

- Social accountability approaches, such as community dialogues, community scorecards, and facility site visits, can help establish linkages between communities and health facilities and provide opportunities for expressing client concerns about important issues such as poor quality of care during childbirth, infant feeding counseling, fears related to vaccine safety, access to clean water to health providers and officials, and begin developing plans for improving service quality or dispelling misconceptions.

\section{Distrust}

- In addition to enabling community engagement for service quality improvement efforts, implementing partners may consider designing specific campaigns to address distrust of service providers and facilities. A potential campaign could invite beneficiaries to formally share their positive experiences with services, as well as suggestions for improving existing services and the standards of care for mothers during childbirth. The recent praise for midwives' lauding their efforts during the Covid-19 outbreak provide an opportunity and example for employing social accountability approaches to re-engage public conversation and re-think current perceptions of $\mathrm{MCH}$ practitioners in Burkina Faso.

\section{Role of family, social support, and environment}

- The umbrella campaign should consider a unifying theme focused on how community members, families, and in particular domestic partners can provide support in adopting priority health behaviors. Specifically, domestic partners, family members, and religious leaders can help to improve $\mathrm{MCH}$ (e.g., facility-based delivery), child nutrition (e.g., breastfeeding), and adoption of FP methods by providing women with the agency and resources to achieve their desired health goals.

- The umbrella campaign should promote strategies fostering improved partner support and communication skills that facilitate adoption of healthy $\mathrm{MCH}$ behaviors including support during childbirth, early adoption and continuation of breastfeeding, and FP methods.
- In consideration of gender attitudes that cut across multiple health areas, promote conversations that normalize the idea that women should have the right to make their own SRH and FP choices, as well as being valued for their contributions to society. Specifically, the campaign should emphasize messages that mitigate harmful gender norms that do not support women's SRH, reduce shame and stigma of associated with women's contraceptive access and procurement, and promote dialogues on combatting gender-based violence, particularly in relation to child marriage.

\section{Emerging conversations related to Covid-19}

- The emergence of Covid-19 in March 2020 reinforced existing challenges related to health system mistrust and misinformation and increased the fragility of vulnerable populations. Additional efforts should be made to understand inequities and factors contributing to increased health and socioeconomic vulnerabilities among certain populations, such as those whose economic livelihoods became significantly compromised, in addition to food insecure children who lost their access to school-provided meals, those without access to clean water supply, or those without ready access to accurate health information and education, so resources can be directed to those most in need. 


\section{References}

1. Train, T. 2020. "What is social listening, why it matters, and 10 tools to make it easier" [Internet]. Available from: https:// blog.hootsuite.com/social-listening-business/\#whatis

2. Breakthrough RESEARCH. 2020. "Informing social and behavior change programs using social listening and social monitoring." Washington, D.C.: Population Council.

3. Hagg, E., V. S. Dahinten, and L. M. Currie. 2018. "The emerging use of social media for health-related purposes in low and middle-income countries: A scoping review," International Journal of Medical Informatics 115: 92-105. doi: 10.1016/j. ijmedinf.2018.04.010

4. Kemp, S. 2020. "Digital 2020: 3.8 billion people use social media" [Internet]. Available from: https://wearesocial.com/ blog/2020/01/digital-2020-3-8-billion-people-use-socialmedia

5. GSM Association. 2019. "Connected women: The mobile gender gap report 2019" [Internet]. Available from: https:// www.gsma.com/mobilefordevelopment/wp-content/ uploads/2019/02/GSMA-The-Mobile-Gender-Gap-Report-2019.pdf

6. The World Bank. 2017. "Individuals using the internetBurkina Faso." International Telecommunication Union (ITU) World Telecommunication/ICT Indicators Database. Available from: https://data.worldbank.org/indicator/IT.NET. USER.ZS?locations=BF.

7. Dougherty, L., and J. Pinchoff. 2020. "Evidence to inform an integrated social and behavior change strategy in the Sahel." Washington D.C.: Population Council.

8. "Viamo 3-2-1- service" [Internet]. Available from: https://viamo.io/services/3-2-1/

9. M\&C Saatchi Intelligence. 2020. "RISE II Program Support Report. Burkina Faso: A social listening and press coverage analysis report, July." M\&C Saatchi Intelligence.

10. M\&C Saatchi Intelligence. 2020. "RISE II Program Support Report. Burkina Faso. A social listening and press coverage analysis report, September." M\&C Saatchi Intelligence.

11. M\&C Saatchi Intelligence. 2020. "Family planning in West Africa. Social listening report. Baseline understanding." M\&C Saatchi Intelligence.

12. Institut National de la Statistique et de la Démographie, ICF International, Programme National de Lutte contre le Paludisme. 2014. "Enquête sur les Indicateurs du Paludisme au Burkina Faso (EIPBF)." Ouagadougou, Burkina Faso.

13. Institut National de la Statistique et de la Démographie (INSD) et ICF International. 2012. "Enquête Démographique et de Santé et à Indicateurs Multiples du Burkina Faso 2010." INSD et ICF International.

14. Pugliese-Garcia, M. et al. 2018. "Factors influencing vaccine acceptance and hesitancy in three informal settlements in Lusaka, Zambia," Vaccine 36(37): 5617-24.

15. Ghinai, I. et al. 2013. "Listening to the rumours: What the northern Nigeria polio vaccine boycott can tell us ten years on," Global Public Health 8(10): 1138-50. doi: 10.1080/17441692.2013.859720
16. Heyerdahl, L. W. et al. 2019. "'It depends how one understands it:' a qualitative study on differential uptake of oral cholera vaccine in three compounds in Lusaka, Zambia," BMC Infectious Diseases 19(1): 421. doi: 10.1186/s12879-0194072-6

17. Reuters. 2020. "French doctor apologises for suggesting COVID-19 treatment be tested in Africa" [Internet]. Available from: https://www.reuters.com/article/us-health-coronavirus-africa-apology/french-doctor-apologises-for-suggesting-covid-19-treatment-be-tested-in-africa-idUSKBN21L2MS

18. PMA2020. 2018. "PMA2020/Burkina Faso: Family planning brief. November 2017-January 2018 (Round 5)." PMA2020.

19. Bankole, A. 2007. "Sexual behavior, knowledge and information sources of very young adolescents in four sub-Saharan African countries," African Journal of Reproductive Health 11(3): $28-43$ 


\section{Population Council}

4301 Connecticut Ave., NW | Suite 280

Washington, DC 20008

+12022379400

breakthroughactionandresearch.org 